\title{
Efecto de la cadena de frío en la preservación de los productos pesqueros
}

\author{
Delcis Milenia Rodríguez, Jorge Humberto Cárcamo ${ }^{1}$ \\ Edgar Osiris Carranza Espinal ${ }^{2}$
}

\section{RESUMEN}

En Honduras la pesca se realiza en las costas del Caribe y el Pacífico, en la cual el más beneficiado es el intermediario, ya que establece con los pescadores artesanales un bajo precio de compra de los productos pesqueros y realizan la manipulación de los productos sin las medidas adecuadas de higiene y conservación.

La industria acuícola usa como indicador de la calidad la mínima presencia de bacterias como Escherichia coli y coliformes totales. Para minimizar la presencia de estas bacterias, la industria usa la cadena de frío; sin embargo, existe la carencia de un estudio que determine el efecto de esta cadena en los productos pesqueros.

En consecuencia, el objetivo del estudio fue evaluar el efecto microbiológico de la cadena de frío en la preservación de los productos pesqueros y encontrar la satisfacción de los compradores en los productos pesqueros en el municipio de Choluteca.

El estudio se realizó en dos etapas, en la primera se colectaron muestras de pescado y se trataron con el método de preservación de la cadena de frío y el procedimiento tradicional del pescador, se comparó el crecimiento microbiológico de Escherichia coli y coliformes totales a las 6, 24 y 36 horas postratamiento; en la segunda fase del experimento se aplicaron 383 cuestionarios en los consumidores finales del municipio de Choluteca, para conocer la satisfacción y preferencia de compra de los productos pesqueros.

Se encontró que el método de cadena de frío reduce el crecimiento de colonias de bacterias y que los compradores finales están dispuestos a pagar hasta un $10 \%$ más por los productos pesqueros tratados con inocuidad y cadena de frío.

Palabras clave: cadena de frío, método tradicional, productos pesqueros.

\footnotetext{
${ }^{1}$ Estudiantes de Ingeniería en Ciencias Acuícolas y Recursos Marino Costeros, CURLP-UNAH.

${ }^{2}$ Asesor, Departamento de Acuicultura y Biología Marina, CURLP-UNAH. Contacto: edgar_osiris_carranza@yahoo.com; edgar.carranza@unah.edu
} 


\section{ABSTRACT}

In Honduras the fishing is done on the Caribbean coast and the Pacific, the biggest winner is the intermediary and establishing a low purchase price of fishery products with artisanal and perform the handling of products without proper hygiene measures and conservation. The aquaculture industry used as a quality indicator minimal presence of bacteria such as Escherichia coli and total coliforms, to minimize the presence of these bacteria industry uses the cold chain. There is a lack of a study to determine the effect of the cold chain in fish products. The aim of the study was to value the microbiological effect of the cold chain in the preservation of fishery products and the satisfaction of finding buyers in fishery products in the town of Choluteca. The study was conducted in two stages, the first fish samples were collected and treated with the method of preservation of the cold chain and the traditional method of fishing, microbiological growth compared Escherichia coli and total coliforms in at six post - treatment , 24 and 36 hours, the second phase of the experiment 383 questionnaires were applied on the final consumers of the municipality of Choluteca satisfaction and preference for purchase of fishery products. It was found that the method of cold chain reduces the growth of bacterial colonies and the end buyers are willing to pay up to $10 \%$ more for seafood safety and treated with cold chain.

Key Words: cold chain, traditional method, fishery products.

\section{INTRODUCCIÓN}

La pesca es una actividad generadora de empleo e ingresos para muchas familias porque mantiene la seguridad alimentaria y nutricional (Gutiérrez, 2005). En 2010, la pesca y la acuicultura aportaron al producto interno bruto de América Latina y el Caribe el 6.6 \%, lo que representó un ingreso de USD 251,194.2 millones para las naciones del continente (CEPAL, 2012). El pescado y los productos pesqueros representaron en el año 2006, el $15 \%$ del consumo de proteína de origen animal en más de 2,900 millones de personas (Gómez, 2007). Los productos de pesca se han convertido en una parte importante de la alimentación en el mundo.

En Honduras, la pesca se realiza en las costas del Caribe y el Pacífico, en el lago de Yojoa y en la Represa Hidroeléctrica Francisco Morazán. La costa pacífica tiene una distancia de $162 \mathrm{~km}$ y una plataforma continental de $5,000 \mathrm{~km}^{2}$, que son las aguas del golfo de Fonseca; de la franja costera y las islas que pertenecen a Honduras, las más importantes son las islas de El Tigre, Zacate Grande, Exposición, San Carlos e Inglesera (FAO, 2002). 
De la actividad de la pesca, el mayor beneficiado es el intermediario, puesto que define un bajo precio de compra de los productos pesqueros con los pescadores artesanales y logran rentabilidades hasta del $100 \%$ con la venta; además, acaparan el mercado, limitan la participación directa de los pescadores y los comprometen para que no tengan otras opciones de comercialización (Espinal, 2013).

Los productos pesqueros que los intermediarios comercializan son inseguros para el consumo por la alta carga microbiológica que adquieren al no contar con el tratamiento adecuado, de manera que se convierten en vehículo para transmitir enfermedades como el cólera, la tifoidea, hepatitis y la poliomielitis (OMS y FAO, 2009). Los productos pesqueros más peligrosos son aquellos que se han capturado cerca de la costa y en regiones con alta densidad poblacional (Galan, Luna y García, 2011). Los pescadores y comercializadores realizan la manipulación de los productos de la pesca sin las medidas de conservación, manipulación e higienización apropiada. Los pescadores filetean y lavan el producto en la orilla de los desembarcaderos, adquiriendo un alto grado de contaminación y dañando la calidad de estos productos (Turcios, 2013).

El pescado y los productos pesqueros son de los alimentos más nutritivos y de los que más fácil se deterioran debido a la acción negativa de las elevadas temperaturas y las malas prácticas durante la manipulación (Avdalov, 2009). El pescado después de ser capturado se deteriora rápidamente por la acción de las enzimas inosina nucleosidasa, miokinasa, AMP-desanimasa y la IPMfosfohidrolasa, que están presentes en la producción posmortem, poniendo rígido al animal e iniciando el proceso de descomposición que provoca el ablandamiento en todo el tejido muscular (Departamento de Pesca, 2013).

También existe la presencia de la flora bacteriana que se encuentra en la superficie externa (piel y branquias) e intestinos del pez, tales como Bacillus, Micrococcus, Clostridium, Lactobacillus, Pseudomonas, Moraxella, Acinetobacter, Shewanella, Flavobacterium, Vibrionáceas (vibrio y photobacterium) y aeromonadáceas (Aeromonas spp.). Estos organismos se reproducen exponencialmente cuando no se manejan temperaturas menores a los $10^{\circ} \mathrm{C}(\mathrm{ICMSF}, 2001)$.

Las bacterias que predominan en el pescado descompuesto a temperaturas altas $\left(14-37^{\circ} \mathrm{C}\right.$ ) son Aeromonas, Vibrio y bacterias coliformes (Avdalov, 2009), las cuales son peligrosas para la salud humana. El crecimiento bacteriano es el principal factor que limita el tiempo de vida comercial del pescado, produciendo su alteración y la aparición de olores desagradables. La estimación del recuento total de bacterias viables presentes en el proceso de descomposición se han utilizado como indicadores de la calidad del pescado (Departamento de Pesca, 2013). 
La industria acuícola en la zona sur usa como indicador de la calidad del producto la mínima presencia de bacterias como Escherichia coli, Shigella sp., Sthapylococcus aureus y los coliformes (Gómez, 2013). Estas bacterias se presentan durante la manipulación del producto y su presencia es motivo de rechazo del camarón empacado en los mercados internacionales. Para minimizar la presencia de bacterias patógenas, la industria acuícola usa la cadena de frío desde la cosecha hasta la compra por el consumidor final (Avdalov, 2009).

La cadena de frío alarga el proceso de descomposición de los alimentos perecederos; pero, para mantener la calidad y salubridad deben estar sometidos a la acción del frío controlado sin interrupción (Ubiarco, 2012). La cadena de frío nace con la necesidad de transportar alimentos perecederos a mercados lejanos, sin que estos se descompongan. Consiste en la adición de hielo al producto desde su cosecha (ICMSF, 2001). En acuicultura, la cadena de frío es la adición suficiente de hielo, manteniendo una relación de hielo producto de 1:1 durante la cosecha hasta su congelamiento y el mantenimiento del producto congelado hasta su consumo (Gómez, 2013). La cadena de frío previene el desarrollo microbiológico de bacterias que afectan la inocuidad del producto.

El no usar la cantidad adecuada de hielo en la actividad pesquera puede ocasionar contaminación del producto, lo cual es peligroso para el consumidor, pero existe la carencia de un estudio que determine el efecto de la cadena de frío en los productos pesqueros para mejorar la calidad y reducir la carga microbiológica.

\section{OBJETIVOS}

\section{Objetivo general}

Evaluar el efecto microbiológico de la cadena de frío en la preservación de los productos pesqueros y encontrar la satisfacción de los compradores en los productos pesqueros para mejorar la calidad e inocuidad de estos alimentos en el municipio de Choluteca.

\section{Objetivos específicos}

1. Comparar el crecimiento microbiológico de Escherichia coliy coliformes totales a las 6,24 y 36 horas de almacenamiento en los productos pesqueros tratados con el método de la cadena de frío y el método tradicional.

2. Encontrar en los consumidores finales de los productos pesqueros de Choluteca, la preferencia y la satisfacción de compra. 
3. Determinar el nivel de conocimiento sobre inocuidad alimentaria y la cadena de frío en los productos pesqueros en la ciudad de Choluteca.

\section{METODOLOGÍA}

\section{Entorno}

El estudio se desarrolló en dos etapas. La primera fase se realizó en el laboratorio de microbiología del Centro Universitario Regional del Litoral Pacífico (CURLP) y se utilizó pescado fresco adquirido de primera venta en la playa de la comunidad pesquera de Cedeño, Choluteca. El pescado fue dividido en dos muestras de 5 kilogramos cada una y se prepararon usando el método de cadena de frío y método tradicional.

Las muestras tratadas con el método de cadena de frío consistió en preservar el producto pesquero en una relación de hielo y producto de 1:1. La manipulación del producto se realizó en el laboratorio de microbiología del CURLP y consistió en la extracción de vísceras, intestinos, branquias y escamas, manejando buenas prácticas de manufactura. Posteriormente, el producto se almacenó por 36 horas en hieleras, mantenido en hielo con una relación 1:1; el hielo usado fue en forma de escarcha, que es recomendado para la preservación de productos pesqueros y adquirido en una planta agroexportadora de camarón cultivado que cuenta con certificación de sistemas de calidad.

Las muestras tratadas con el método tradicional fueron procesadas según el procedimiento del pescador y acopiador, desde la captura hasta la comercialización. La extracción de vísceras, intestinos, branquias y escamas se realizó en el desembarcadero de la comunidad y el hielo que se usó fue fabricado por el pescador. Los productos se almacenaron en hielera y la cantidad de hielo usado para mantener el producto por 36 horas fue el recomendado por el pescador.

\section{Diseño}

Se usó el diseño factorial de un diseño experimental para el análisis de las muestras de pescado. Este se almacenó en dos hieleras, se dividió en 12 porciones de 416 gramos de producto cada uno y se envasaron en bolsa plásticas estériles; cada porción de pescado fue una repetición o réplica para el análisis del experimento.

El pescado de cada una de las 12 muestras de las dos hieleras fue frotado con hisopos esterilizados en la piel y tejido muscular, recorriendo el área de un 
centímetro cuadrado e introducidos en tubos de ensayos que contenían agua peptonada tamponada (APT). Los hisopos usados para la recolección de las muestras microbiológicas fueron los recomendados para este tipo de procedimiento de microbiología. Para cada muestra se usó un hisopo con su respectivaAPT.

Este procedimiento se realizó a las 6, 24 y 36 horas después de haber tratado el pescado con los dos métodos de preservación (cadena de frío y tradicional). En cada tiempo que se recolectó el contenido microbiológico del pescado se usaron cuatro repeticiones por método. EI APT que contenía la carga microbiológica de las muestras de pescado fue diluido en la proporción de 1:10, diluyendo un $\mathrm{ml}$ de la muestra en $9 \mathrm{ml}$ de APT esterilizado, este procedimiento es recomendado para tener una mejor lectura al momento del conteo de las colonias de microorganismos (Bastidas, Calpa y Ramírez, 2014).

A cada muestra diluida se aplicó un mililitro sobre placas petrifilm ${ }^{\mathrm{TM}}$ para recuento de $E$. coli y coliformes totales; estas placas se incubaron a $35^{\circ} \mathrm{C}$ durante 48 horas y se contaron las colonias de $E$. coli y coliformes totales detectadas. Las placas petrifilm para el recuento de $E$. coli y coliformes totales proporcionan resultados que son equivalentes a los de la prueba de tres placas de agar Baird Parker y reacción de coagulasa, combinadas en una sola prueba. Los resultados son rápidos y confiables obteniéndose entre 24 y 48 horas, en comparación con las 69 horas requeridas por las pruebas convencionales (Alonso y Poveda, 2008).

La detección del E. colien las placas petrifilm ocurre porque las bacterias producen beta-glucuronidasa y simultáneamente presentan una precipitación azul que es asociada con la colonia. La película superior del petrifilm atrapa el gas producido por la $E$. coli y los coliformes fermentadores de lactosa. Se estima que el $95 \%$ de las $E$. coli producen gas y es detectado en la placa pretrifilm, presentando una coloración de las colonias entre azules y rojo-azules (Lerena y Lerena, 2014).

Para el conteo de las colonias se usó la guía de interpretación de placas petrifilm para el recuento de E. coli y coliformes totales (3M seguridad alimentaria, 2009), empleando como unidad de medida las unidades formadoras de colonias por mililitro (UFC/ml).

\section{Población}

En la segunda fase del experimento se aplicó un cuestionario para determinar el nivel de conocimiento sobre inocuidad y tratamiento de la cadena de frío en el 
municipio de Choluteca. Para encontrar la muestra se usó el método de muestreo proporcional para una población conocida. Como la población del municipio de Choluteca es de 169,113 personas, la muestra después de aplicar la técnica de muestreo fue de 383.

A esta muestra se le aplicó el instrumento dirigido a los consumidores finales de los productos pesqueros entre los meses de agosto a diciembre de 2013. La fórmula del muestreo proporcional para una población conocida usada en la investigación es la siguiente:

$$
\begin{aligned}
& n=\frac{1.96^{*}(0.5)^{*}(0.5)^{*} 169,113}{(0.05)^{*}(169,112)+(1.96)^{*}(0.5)^{*}(0.5)} \\
& n=383 \quad n=\frac{Z^{2}{ }_{\alpha / 2} P Q N}{\varepsilon^{2}(N-1)+Z P Q}
\end{aligned}
$$

La selección de los encuestados en la aplicación de los instrumentos fue aleatoria y se hizo en los lugares de mayor tránsito de personas del municipio, como centros comerciales, supermercados y mercados municipales de la ciudad. En el instrumento se preguntó sobre el lugar de compra del producto pesquero, tipo de producto pesquero que se compra, satisfacción por la compra del producto, inocuidad, cadena de frío, disposición para pagar por los productos pesqueros y principales razones por las que no se consumen productos pesqueros.

\section{Análisis estadístico}

En el análisis de las muestras de la primera fase se usó un diseño factorial de 2X3X4, que son: dos métodos de preservación de los productos pesqueros (cadena de frío y método tradicional por el pescador), tres tiempo de preservación del producto $(6,24$ y 36 horas después de la preparación del producto) y cuatro repeticiones, sumando 24 unidades de análisis 0 unidades experimentales (2X3X4).

Se analizó el efecto del tiempo de almacenamiento de los productos pesqueros y los métodos de manipulación y almacenamiento, comparando la presencia de Escherichia coli y coliformes totales en las muestras recolectadas. Para la comparación de medias de los tratamientos se usó la diferencia mínima significativa al 0.05 de significancia. Los análisis estadístico se hicieron con el software Infoestat@. Para conocer los resultados de los instrumentos aplicados en la muestra 
de la población del municipio de Choluteca, se usó estadística descriptiva y se transformaron los valores a porcentajes.

\section{RESULTADOS}

\section{Resultados microbiológicos}

En el análisis microbiológico no se detectaron colonias de Escherichia coli en ninguna de las muestras incubadas en las placas de petrifilm según los dos métodos de preservación, esto se pudo deber a que el producto pesquero fue adquirido en primera venta y la manipulación fue menor en comparación al producto que es comercializado en los puestos de venta, en donde intervienen muchos actores de la cadena de comercialización de los productos pesqueros y la incidencia de $E$. coli es mayor, sobre todo cuando no son manejado apropiadamente (Avdalov, 2009).

La Escherichia coli es utilizada como microorganismo indicador de contaminación fecal del alimento y habita en el suelo, agua, polvo, alimentos y principalmente en el tracto intestinal del hombre y animales de sangre caliente; su forma de transmisión es por el contacto de las heces con el agua y los alimentos y provoca enfermedad cuando los productos pesqueros no se han preparado en forma adecuada y son manipulados constantemente sin las normas apropiadas de higiene e inocuidad (Páez, 2009).

En ambos métodos se encontraron colonias de coliformes totales, siendo el método de preservación tradicional el que presentó mayor crecimiento microbiológico (ver gráfico 1). Según el estudio, la cadena de frío presentó un crecimiento máximo menor de $4.8 \times 10^{-3}$ de UFC/ml de coliformes totales, en comparación al método tradicional que desarrolló hasta $4.6 \times 10^{-5} \mathrm{de}$ UFC/ml. Entre ambos métodos de preservación se encontraron diferencias estadísticas significativas $(P>0.0262)$, siendo el método de la cadena de frío el que mostró el menor crecimiento de UFC por $\mathrm{ml}(P>0.05)$. El límite máximo permitido de coliformes es de 460 según el número más probable de colonias por gramo o mililitro, conforma al Reglamento Técnico Centroamericano (MINECO, CONACYT, MIFIC, SIC y MEIC, 2014) 0 menor de 1,000 unidades formadoras de colonias por mililitro (Páez, 2009).

A las seis horas postratamiento en las muestras con la cadena de frío, las unidades formadoras de colonias (UFC) desarrolladas estuvieron en el límite máximo permisible; a las 24 horas se incrementó en un $43 \%$ y a las 36 horas el crecimiento microbiológico fue del $79 \%$ más de los resultados a seis horas postratamientos. 
Con el método tradicional las muestras a las seis horas desarrollaron el doble de UFC del límite máximo permisible de coliformes totales (1,000 UFC/ml), a las 24 horas las UFC se incrementaron en un $75 \%$ y a las 36 horas el crecimiento fue de 459 veces más que el límite máximo permitido (ver gráfico 1 ).

Gráfico 1. Coliformes totales por mililitro

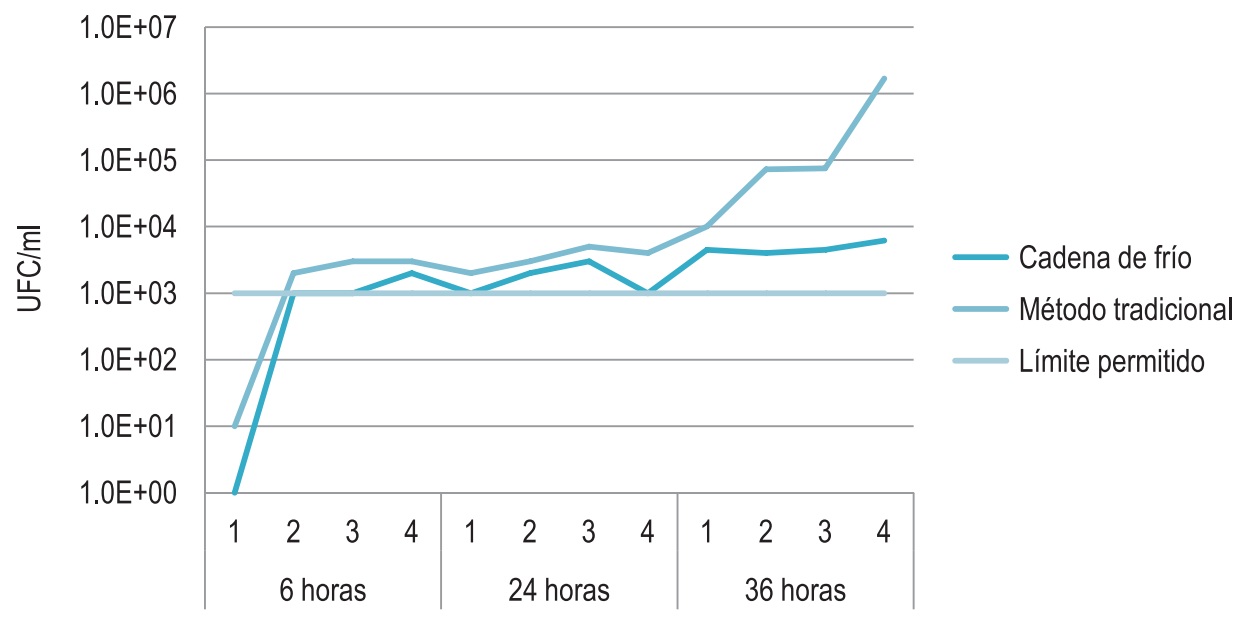

En los tres tiempos de análisis de las muestras (6, 24 y 36 horas) las diferencias estadísticas fueron concluyentes ( $P>0.0092)$; así, el mayor crecimiento de los coliformes totales se detectó a las 36 horas con el método tradicional, siendo estadísticamente diferente a los resultados microbiológicos de las muestras analizadas. Las colonias detectadas a las 6 y 24 horas postratamiento no fueron estadísticamente concluyentes $(P<0.05)$. El efecto de la cadena de frío para reducir la población microbiológica se observó después de las 36 horas postratamiento. Los coliformes totales crecen entre los $10^{\circ} \mathrm{C}$ y $40{ }^{\circ} \mathrm{C}$ y su crecimiento es limitado a temperaturas inferiores a los $5^{\circ} \mathrm{C}$ (Alonso y Poveda, 2008).

En los productos pesqueros los coliformes se desarrollan por la presencia de heces humanas y de animales en los cuerpos de agua cerca de asentamientos humanos; pero, cuando la captura de los peces es lejos de la costa, la presencia de coliformes es menor que en los peces capturados en los estuarios (Galan, Luna y García, 2011). Al igual que la $E$. coli, los coliformes totales son considerados indicadores de la calidad del alimento y se transmiten al ser humano por medio de la ingesta de alimentos contaminados, los cuales se contaminan por el contacto directo con el agua expuesta a las heces fecales y la falta de higiene en la manipulación del alimento (Páez, 2009). 
Inocuidad y cadena de frío en los productos pesqueros

En el diagnóstico se encontró que el $79 \%$ de los encuestados consumen productos pesqueros y de estos el $59 \%$ los compra en el mercado municipal, el $23 \%$ en el supermercado y el $18 \%$ en el barrio o colonia. También se encontró que los productos pesqueros que los consumidores prefieren comprar (ver gráfico 2) son la corvina o babosa que comprende cinco especies (Cynoscion reticulatus, Cynoscion albus, Cynoscion squamipinnis, Cynoscion phoxocephalus y Nebris occidentales) y el camarón blanco (Litopenaeus vannamei) capturado en alta mar, con tallas de entre 5 a 20 camarones por libra. Los consumidores prefieren la corvina y el camarón blanco a pesar de que estas especies tienen un valor comercial superior a otros productos como los crustáceos y el pescado blanco, que son especies de peces de carne blanca (pancha, ruco, barbudo, palometa, bagre y otros).

En menor preferencia se encontró el pargo (Lutjanus peru, Lutjanus novemfaciatus y Lutjanus colorado) y el róbalo (Centropomus spp.), especies que tienen un mayor valor comercial que la babosa en el mercado nacional (ver gráfico 2). Las capturas de estas especies disminuyen en algunos meses del año por la disponibilidad del recurso pesquero en el medio natural, incrementando su valor en los meses de menor captura.

Choluteca es una ciudad que se encuentra a menos de 30 minutos de la costa del Pacífico y la preferencia de los consumidores por los productos pequeros de origen marino es mayor que los productos pesqueros de agua dulce como la tilapia, sin embargo, en el estudio se encontró que el curil, las jaibas y la tilapia tienen igual preferencia de compra. 
Gráfico 2. Preferencia de compra de los consumidores de productos pesqueros en Choluteca, 2013

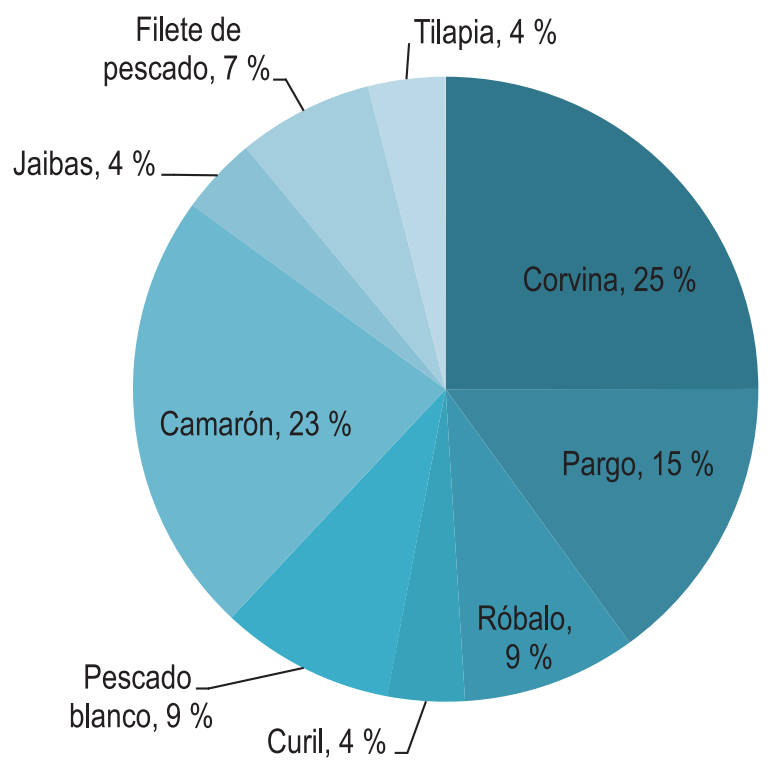

Se encontró que el $80 \%$ de los encuestados que compran productos pesqueros tienen satisfacción por lo que compran con relación al precio y frescura, pero no en cuanto a calidad e higiene del producto. También se descubrió que los consumidores están desinformados en cuanto a inocuidad y cadena de frío, ya que el $56 \%$ de los entrevistados desconoce los principios básicos de inocuidad alimentaria y el $60 \%$ no sabe sobre la cadena de frío.

En el $84 \%$ de los consumidores finales se encontró que tienen disposición para pagar hasta un $10 \%$ más por los productos pesqueros que sean manejados con inocuidad y reciban un tratamiento de cadena frío. En los comercializadores (pesquerías, centros de ventas, vendedores ambulantes y supermercados) se encontró que el $69 \%$ tiene conocimiento sobre inocuidad y que el $77 \%$ de ellos están dispuestos a comprar a un mayor precio los productos pesqueros si son tratados con inocuidad y se mantienen frescos con el uso de la cadena frío.

Estos resultados apoyan la necesidad de manejar los productos pesqueros con inocuidad, capacitar a los compradores y comercializadores sobre inocuidad alimentaria para mejorar la calidad de los productos pesqueros y fortalecer la cadena de comercialización de los productos pesqueros incrementando la participación de las autoridades competentes para regular la comercialización de estos productos con calidad, mejorando la actividad comercial del pescador. 


\section{CONCLUSIONES}

El menor crecimiento microbiológico de coliformes totales se encontró en los productos tratados con el método de cadena de frío a las 24 y 36 horas postratamiento de las muestras; en ambos métodos se observó crecimiento de las colonias superando el límite permitido de 1,000 UFC/ml, pero este crecimiento fue inferior a las 10,000 UFC/ml en el método de la cadena de frío, en comparación al método tradicional que superó el 1,000,000 UFC/ml de coliformes totales.

En los dos métodos de preservación de los productos pesqueros no se detectaron colonias Escherichia coli, ya que se redujo la manipulación del producto durante el experimento. Este es un microorganismo indicador de contaminación fecal del alimento y se trasmite a los alimento por el contacto de las heces humanas con las manos.

La mayor parte de los compradores de productos pesqueros de Choluteca, compran en los mercados municipales; siendo la corvina, el camarón y el pargo, los productos que tienen la mayor preferencia de compra. Existe satisfacción de los compradores por los productos que compran en cuanto a frescura y precio, pero no en higiene y calidad.

El $84 \%$ de los consumidores tienen la disposición de pagar hasta un $10 \%$ más por los productos pesqueros que sean manejados con inocuidad y reciban un tratamiento de cadena frío; en los comercializadores, el $77 \%$ están dispuestos a comprar un mayor valor los productos pesqueros tratados con la cadena de frío y manejados con inocuidad.

\section{BIBLIOGRAFÍA}

Alonso, L. y Poveda, J. (2008). Estudio comparativo en técnicas de recuento rápido en el mercado y placas petrifilm $3 \mathrm{M}$ para el análisis de alimento. Colombia: Pontificia Universidad Javeriana.

Andara, C. y Sánchez, E. (2011). Documento de formulación del proyecto de desarrollo de actividades acuícolas en el Golfo de Fonseca. Tegucigalpa: OTC.

Avdalov, N. (2009). Manual de control de calidad y manipulación de productos pesqueros para pescadores y procesadores artesanales. México: Infopesca.

Bastidas, L. F.; Calpa, J. y Ramírez, I. (2014). Evaluación sanitaria de la calidad microbiologica de los productos acuícolas en la ciudad de San Juan de Pasto.

Centro de Estudios en Salud. Recuperado de:

http://scienti.colciencias.gov.co:8084/publindex/docs/articulos/0124-

7107/2291649/2304951.pdf 
CEPAL. (2012). Anuario Estadístico de América Latina y el Caribe. Santiago de Chile: Naciones Unidades.

Departamento de Pesca. (2013). Cambios posmortem en el pescado. FAO. Recuperado de: $\mathrm{http}: / /$ www.fao.org/docrep/v7180s/v7180s06.htm

Espinal, A. (06 de junio de 2013). Intermediarios hacen más desgraciada la vida del pescador. El Heraldo. Recuperado de: http://www.elheraldo.hn/SeccionesPrincipales/Al-Frente/Intermediarios-hacen-mas-desgraciada-la-vida-delpescador

FAO. (2002). Analisis de la pesca artesanal en Honduras. Recuperado de: http://www.fao.org/fi/oldsite/FCP/es/hnd/profile.htm

FAO. (2008). Estadística de pesca y acuícultura. Italia: FAO.

FAO. (2010). El estado muncial de la pesca y la acuícultura. Italia: Departamento de Pesca y Acuicultura de FAO.

FAO. (2011). Examen de la pesca y la acuicultura en el mundo. FAO. Recuperado de: http://www.fao.org/docrep/003/w3265s/w3265s02.htm

FAO. (2012). Examen mundial de la pesca y la acuicultura 2012. Italia: Departamento de Pesca y Acuicultura de la FAO.

Galan, L.; Luna, H. y García, J. (2011). Control de calidad de productos pesqueros. México: Universidad Nacional de México.

Gómez, E. (2007). Mejoramiento de los mercados internos de los productos pesqueros en América Latina y el Caribe. Colombia: Infopesca.

Gutiérrez, C. (2005). Pesca en América Latina: un enfoque ecosistémico para la rentabilidad económica. Recuperado de: http://www.ecoportal.net/EcoNoticias/Pesca_en_America_Latina_enfoque_ecosistemico_para_la_rentabilid ad_economica

ICMSF. (2001). Microbiología de los alimentos: ecología microbiana de los productos alimentarios. España: ACRIBIA.

Lerena, C. y Lerena, J. (2014). Manual estándares de límites críticos.

Recuperado de: http://blogsdelagente.com/blogfiles/fundacion-agustinalerena/221508_CienciasNaturales1.50ManualdeL\%C3\%ADmitesCr\%C3\%ADti cos.pdf

MINECO, CONACYT, MIFIC, SIC y MEIC. (2014). Alimentos. Criterios microbiologicos para la inocuidad de alimentos. Reglamento Técnico Centroamericano. Recuperado de:

http://www.itp.gob.pe/normatividad/demos/doc/Normas\%20Internacionales/OT ROS/Centro\%20america/CriteriosMicrobiolgicos.pdf

Naciones Unidas. (2010). Panorama de la situación de la pesca en el mundo. Conferencia de revisión continuada del acuerdo relativo a la conservación y ordenamiento de poblaciones de peces tranzonales y las poblaciones de peces altamente migratorios. New York: Naciones Unidas. 
OMS y FAO. (2009). Código de prácticas para el pescado y los productos pesqueros. Italia: OMS-FAO.

OPTI. (2009). Estudio de propestiva para la cadena productiva de la industria pesquera en la región de la costa sur del Pacífico. Colombia: Ministerio de Comercio, Industria y Turismo.

Ubiarco, V. (2012). Perecederos. Profesionalización en la cadena de frío.

Recuperado de:

http://www.enfasis.com/Presentaciones/LS/2012/Talleres/Ubiarco.pdf

3M Seguridad Alimentaria. (2009). Guía de interpretación 3M placas petrifilm.

Recuperado de:

http://jornades.uab.cat/workshopmrama/sites/jornades.uab.cat.workshopmram a/files/Petrifilm_guias.pdf 